\title{
Enteric Murine Ganglionitis Induced by Autoimmune CD8 T Cells Mimics Human Gastrointestinal Dysmotility
}

Monica Sanchez-Ruiz, ${ }^{*}$ Anna Brunn, ${ }^{*}$ Manuel Montesinos-Rongen, ${ }^{*}$ Claudia Rudroff, ${ }^{\dagger}$ Melanie Hartmann, ${ }^{\ddagger}$ Dirk Schlüter, ${ }^{\S \oplus}$ Gabriele Pfitzer, ${ }^{\|}$and Martina Deckert*

Accepted for publication November 28, 2018.

Address correspondence to Martina Deckert, M.D., Department of Neuropathology, University of Cologne, Kerpener St. 62, D-50924 Köln, Germany. E-mail: martina. deckert@uni-koeln.de.

\begin{abstract}
Inflammatory bowel diseases frequently cause gastrointestinal dysmotility, suggesting that they may also affect the enteric nervous system. So far, the precise mechanisms that lead to gastrointestinal dysmotility in inflammatory bowel diseases have not been elucidated. To determine the effect of CD8 T cells on gastrointestinal motility, transgenic mice expressing ovalbumin on enteric neurons were generated. In these mice, adoptive transfer of ovalbumin-specific 0T-I CD8 T cells induced severe enteric ganglionitis. CD8 T cells homed to submucosal and myenteric plexus neurons, $60 \%$ of which were lost, clinically resulting in severely impaired gastrointestinal transition. Anti-interferon- $\gamma$ treatment rescued neurons by preventing their up-regulation of major histocompatibility complex class I antigen, thus preserving gut motility. These preclinical murine data translated well into human gastrointestinal dysmotility. In a series of 30 colonic biopsy specimens from patients with gastrointestinal dysmotility, CD8 T cell-mediated ganglionitis was detected that was followed by severe loss of enteric neurons $(74.8 \%)$. Together, the preclinical and clinical data support the concept that autoimmune CD8 T cells play an important pathogenetic role in gastrointestinal dysmotility and may destroy enteric neurons. (Am J Pathol 2019, 189: 540-551; https://doi.org/10.1016/j.ajpath.2018.11.016)
\end{abstract}

Enteric nervous system (ENS) disturbance is a frequent complication in patients with a variety of inflammatory bowel diseases. The hallmark of ENS disturbance is gastrointestinal (GI) dysmotility that clinically manifests with disabling symptoms of abdominal pain, constipation, diarrhea, and fecal incontinence.

Infections or postinfectious states may cause enteric dysmotility. Up to $10 \%$ of patients develop irritable bowel syndrome subsequent to bacterial gastroenteritis. ${ }^{1,2}$ In these patients, the rectal lamina propria harbors elevated T-cell numbers. ${ }^{3,4}$ The loss of myenteric neurons in experimental colitis $^{5,6}$ raises the question of which mechanisms link inflammation and neuronal damage. Paraneoplastic gut dysmotility is a well-known complication in patients with tumors and anti-Hu antibodies. ${ }^{7-10}$ In addition, antineuronal antibodies are present in the serum of patients with various GI disorders. ${ }^{11}$ These observations support the theory that neuronal antigens can become targets of an immune response. Indeed, in a rat model of chronic functional bowel changes after Campylobacter jejuni infection, a circulating antibody that recognizes the neuronal protein vinculin has been detected. ${ }^{12}$ Although these data indicate that antibodies play a role in GI dysmotility, it is unknown whether they indeed cause neuronal destruction. A role for molecular mimicry between a pathogen and ENS cells is suggested in Chagas disease in which Trypanosoma cruzi flagellar antigen Fl-160 cross-reacts with myenteric

Supported by Deutsche Forschungsgemeinschaft grant De 485/8-3 (M.D.).

Disclosures: None declared. 
neurons. ${ }^{13,14}$ Thus, both cellular and humoral immune reactions likely contribute to GI dysmotility.

To address a potential role of CD8 T cells in this scenario, we designed CKTAC mice, which express ovalbumin (OVA) as autoantigen on enteric neurons. Adoptive transfer (AT) of OVA-specific OT-I CD8 T cells induced severe enteric ganglionitis attributable to a fulminant interferon (IFN)- $\gamma$-mediated CD8 T-cell attack of neurons, resulting in their destruction and, clinically, delayed GI transit progressing to ileus. These experimental data translated well into human disease because CD8 T-cell-mediated ganglionitis leading to severe neuronal loss was identified in the colon of 30 patients with GI dysmotility of previously unknown origin who could not be assigned to a specific disease entity before, thus opening novel therapeutic avenues.

\section{Materials and Methods}

Mice

CKTAC, OT-I, and C57BL/6 mice were used. Mice were kept under specific pathogen-free conditions. In all experiments, animals were examined daily (Table 1). Experiments were performed according to NIH guidelines under permits from the Government of North-Rhine-Westphalia (Cologne, Germany).

\section{Generation of CKTAC Mice}

To generate the conditional knock-in mouse C57Bl/6NTac-

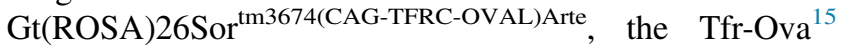

Table 1 Clinical Scoring Algorithm to Assess Gastrointestinal Symptoms in Mice*

\begin{tabular}{ll}
\hline Clinical parameter & Score \\
\hline General condition & \\
$\quad$ Hair coat & \\
$\quad$ Smooth, bright & 0 \\
$\quad$ Rough & 1 \\
Posture & \\
$\quad$ Normal & 0 \\
$\quad$ Hunched & 1 \\
Stool consistency & \\
Normal & 0 \\
Diarrhea/constipation & 1 \\
Body weight loss (\%) & \\
$\quad<2$ & 0 \\
$2-5$ & 1 \\
$5-10$ & 2 \\
$10-15$ & 3 \\
$>15$ & 4 \\
Total score & 7 \\
\hline
\end{tabular}

*Animals were examined daily for clinical signs of gastrointestinal disturbance considering general conditions, stool consistency, and body weight. Each of these conditions was evaluated individually, and their sum was integrated into an overall clinical score. Loss of body weight $>20 \%$ was defined as human end point. open reading frame transgene was inserted in the ROSA 26 locus via targeted transgenesis (Taconic, Cologne, Germany). CKTAC mice were generated by crossing C57B1/

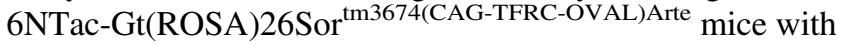
NSE-cre(CK1) mice, ${ }^{16}$ provided by Dr. Luis F. Parada (University of Texas Southwestern Medical Center, Dallas, $\mathrm{TX})$, to drive expression of OVA on neurons.

Both female and male mice ( 8 to 12 weeks old) were included in the experiments because first-line experiments disclosed differences in the ENS as well as in the response of female and male CKTAC mice to AT of OT-I CD8 T cells.

\section{Adoptive Transfer}

CD8 $\mathrm{T}$ cells were isolated from spleen and mesenteric lymph node (MLN) of OT-I mice via MACS (Miltenyi, Bergisch Gladbach, Germany). Freshly isolated OT-I CD8 $\mathrm{T}$ cells were injected intravenously into CKTAC or C57BL/ 6 mice $\left(1 \times 10^{6}\right.$ cells per mouse). Purity of CD8 T cells was $>95 \%$ as determined by flow cytometry.

\section{In Vivo Neutralization of IFN- $\gamma$}

Mice received $250 \mu \mathrm{g}$ of anti-IFN- $\gamma$ (clone XMG1.2; Biolegend, San Diego, CA) or $250 \mu \mathrm{g}$ of rat IgG (SigmaAldrich, Taufkirchen, Germany) intraperitoneally every 2 days starting on the day of OT-I CD8 T cell injection.

\section{In Vivo Inhibition of iNOS}

L- $N^{6}$-iminoethyl-lysine (L-NIL' Cayman Chemical, Ann Harbor, MI) was added to drinking water in a concentration of $1 \mathrm{mg} / \mathrm{mL}$, beginning 3 days before AT. ${ }^{17}$ Control mice received plain drinking water.

\section{In Vivo Depletion of CD4 T Cells}

Mice received $100 \mu \mathrm{g}$ of anti-CD4 (clone GK1.5; Biolegend) or $100 \mu \mathrm{g}$ of isotype-matched rat IgG (SigmaAldrich) intraperitoneally on days $-3,-2,-1,2$, and 4 of OT-I CD8 T-cell injection.

\section{Tissue Preparation and Analysis}

After intracardial perfusion the entire colon was embedded as a "Swiss roll," 18,19 with half snap-frozen and the other half embedded in paraffin. Frozen and paraffin sections were used for histochemistry, immunohistochemistry, and terminal deoxynucleotidyl transferase-mediated dUTP nick-end labeling staining as described previously (Table 2). ${ }^{20,21}$

\section{Force Measurement of Ileal Smooth Muscle}

Colon and ileum of CKTAC mice were morphologically similar in CKTAC with and without AT of OT-I CD8 T cells, respectively. Thus, force was measured in ileal smooth 
Table 2 Antibodies Used for Immunofluorescence and Immunohistochemistry in Mice

\begin{tabular}{|c|c|c|c|}
\hline Antibody & Clone & Company & Species \\
\hline \multicolumn{4}{|l|}{ Primary } \\
\hline Ovalbumin & Polyclonal & Sigma-Aldrich & Rabbit \\
\hline$\beta$-III-tubulin & Polyclonal & Abcam, Cambridge, UK & Rabbit \\
\hline$\beta$-III-tubulin & Monoclonal & Abcam & Mouse \\
\hline $\mathrm{Hu} \mathrm{C/D}$ & Polyclonal & Abcam & Rabbit \\
\hline CD34 & EPR18668 & Abcam & Rabbit \\
\hline CD45 (LCA) & M1/9.3.4.HL.2 (hybridoma) & LGC Standards, Wesel, Germany & Rat \\
\hline CD4 & GK1.5 & BD Biosciences, Heidelberg, Germany & Rat \\
\hline CD8a & $53-6.7$ & BD Biosciences & Rat \\
\hline CD8 & SP16 & DCS, Hamburg, Germany & Rabbit \\
\hline MAC-3 & M3/84 & BD Biosciences & Rat \\
\hline Isolectin $\mathrm{GS}-\mathrm{IB}_{4}$ & & Invitrogen, Karlsruhe, Germany & Griffonia simplicifolia \\
\hline MHC class I & M1/42.3.9.8 HLK (hybridoma) & LGC Standards & Rat \\
\hline MHC class II & I-A ${ }^{b, d, q}$ M5.114.15.2 (hybridoma) & LGC Standards & Rat \\
\hline CD44 & EPR18668 & Abcam & Rabbit \\
\hline CD62L & MEL-14 & Abcam & Rat \\
\hline CD69 & $\mathrm{H} 1.2 \mathrm{~F} 3$ & Biolegend, San Diego, CA & Armenian hamster \\
\hline FasL & Polyclonal & Abcam & Rabbit \\
\hline Perforin & CB5.4 & Abcam & Rat \\
\hline iNOS & Polyclonal & Abcam & Rabbit \\
\hline Activated caspase- 3 & C92-605 & BD Biosciences & Rabbit \\
\hline
\end{tabular}

BSP, biotin spacer; FITC, fluorescein isothiocyanate; GFAP, glial fibrillary acidic protein; iNOS, inducible nitric oxide synthase; MHC, major histocompatibility complex.

muscle as previously published. ${ }^{22,23}$ Isometric force elicited by electrical field stimulation and carbachol were recorded with LabChart version 7.0 (AdInstruments, Oxford, UK; sampling rate, $100 \mathrm{~Hz}$ ) and evaluated as area under the curve. The amplitude of spontaneous rhythmic contractions and the area under the curve of electrical field stimulation elicited contractions were normalized to potassium-induced contractions; the dose-response relation to carbachol was normalized to maximal force at $30 \mu \mathrm{mol} / \mathrm{L}$ carbachol.

\section{Flow Cytometry of Splenic and MLN Leukocytes}

Leukocytes were analyzed by double immunofluorescence staining with $\mathrm{CD} 8 \mathrm{a}-$ fluorescein isothiocyanate (FITC), CD4-phosphatidylethanolamine (PE), CD80-PE, CD83-PE, CD69-PE (all from BD Biosciences, Heidelberg, Germany), and $\mathrm{H}-2 \mathrm{~Kb} / \mathrm{SIINFEKL}\left(\mathrm{OVA}_{257-264}\right.$ dextramer)-PE (Immudex, Copenhagen, Denmark). Acquisition was performed on a
FACSVerse (BD Biosciences); data were analyzed using FlowJo software version 10.1 (Treestar, Ashland, OR).

\section{Quantitative RT-PCR of IFN- $\gamma$ mRNA}

RNA extraction from cryopreserved MLN and spleen was performed as described. ${ }^{20}$ IFN- $\gamma$ mRNA transcription was analyzed by quantitative RT-PCR using a Taqman gene expression assay (Applied Biosystems, Darmstadt, Germany). All samples (three animals per group) were studied in triplicate. For normalization, murine TATA box-binding protein and POLR2A were chosen as reference genes.

\section{Studies in Patients with GI Dysmotility}

Thirty patients (Supplemental Table S1) surgically treated for GI dysmotility of unknown origin were included in this 
Table 3 Antibodies Used for Immunohistochemistry and Immunofluorescence Studies of Patients' Colonic Specimens

\begin{tabular}{|c|c|c|c|}
\hline Antibody & Clone & Company & Species \\
\hline \multicolumn{4}{|l|}{ Primary } \\
\hline LCA (CD45) & LJ27.9 & DCS & Mouse \\
\hline CD3 & SP7 & DCS & Rabbit \\
\hline CD4 & 4B12 & $\begin{array}{l}\text { BioGenex, Fremont, } \\
\text { CA }\end{array}$ & Mouse \\
\hline $\mathrm{CD} 8$ & SP16 & DCS & Rabbit \\
\hline CD20 & $\mathrm{L} 26$ & DCS & Mouse \\
\hline CD68 & PG-M1 & DCS & Mouse \\
\hline MHC class I antigen & Polyclonal & $\begin{array}{l}\text { Bioss, Eching, } \\
\text { Germany }\end{array}$ & Rabbit \\
\hline MAP2 protein & $\mathrm{HM}-2$ & Sigma-Aldrich & Mouse \\
\hline$\beta$-III-tubulin & TU-20 & $\begin{array}{l}\text { Abcam, Cambridge, } \\
\text { UK }\end{array}$ & Mouse \\
\hline $\mathrm{Hu} C / \mathrm{D}$ & Polyclonal & Abcam & Rabbit \\
\hline GFAP & GA-5 & BioGenex & Mouse \\
\hline S100 protein & I5E2E2 & DCS & Mouse \\
\hline APP & $22 C 11$ & Millipore & Mouse \\
\hline $\begin{array}{l}\text { Neurofilament } \\
\text { protein }\end{array}$ & $2 \mathrm{~F} 11$ & $\begin{array}{l}\text { Dako, Hamburg, } \\
\text { Germany }\end{array}$ & Mouse \\
\hline c-kit & SP26 & DCS & Rabbit \\
\hline CD34 & QBend/10 & BioGenex & Mouse \\
\hline \multicolumn{4}{|l|}{ Secondary } \\
\hline Goat anti-mouse-Cy3 & & $\begin{array}{l}\text { Dianova, Hamburg, } \\
\text { Germany }\end{array}$ & Goat \\
\hline Goat anti-rabbit BSP & & Dianova & Goat \\
\hline Rat anti-mouse BSP & & Dianova & Rat \\
\hline Extravidin-FITC & & Sigma-Aldrich & \\
\hline
\end{tabular}

BSP, biotin spacer; FITC, fluorescein isothiocyanate; GFAP, glial fibrillary acidic protein; MHC, major histocompatibility complex.

retrospective study. Diagnostic workup was performed according to a diagnostic algorithm (Supplemental Figure S1).

\section{Histochemistry and Immunohistochemistry of Colonic Specimens}

Paraffin sections cut from full-thickness specimens of the distal colon were stained by hematoxylin and eosin, Elastica van Gieson, and cresyl violet. Immunohistochemistry (Table 3) was performed as described. ${ }^{20}$ The study was approved by the Ethics Commission of the Medical Faculty of Cologne University (18-143).

\section{Statistical Analysis}

In animal experiments, differences in clinical disease activity between the respective experimental group and the corresponding control were tested with the $t$-test. The number of CD8 T cells in the enteric neuroenvironment of the colon and the number of enteric neurons was quantitatively assessed by evaluating sections immunostained for CD8 and $\beta$-III-tubulin, respectively, in at least 50 highpower fields (HPF) per section. Six mice per experimental group were analyzed. The $t$-test was applied to determine significance of differences between the respective experimental group and the corresponding control group.

Data derived from force measurements are presented as means \pm SEM. Significance was tested using the $t$-test or two-way analysis of variance followed by Sidak posttest as appropriate. Data analysis was performed with GraphPad Prism software version 7.0 (GraphPad Software, San Diego, CA).

Differences in the number and activation of OVA-specific CD8 $\mathrm{T}$ cells and $\Delta \Delta \mathrm{CT}$ values of IFN- $\gamma$ mRNA transcripts were analyzed in CKTAC mice with and without AT of OTI CD8 $\mathrm{T}$ cells and tested for significance between the respective experimental group and the corresponding control using the $t$-test. Six mice per group were used for the various experiments.

Experiments were performed at least twice. Overall, 317 mice were included in the experiments.

In human specimens, serial sections immunostained with anti-MAP2 and anti-CD8 antibodies were quantitatively evaluated for the number of enteric neurons and CD8 T cells in the ENS microenvironment, respectively. At least $25 \mathrm{HPF}$ per section were analyzed per patient. To test for differences
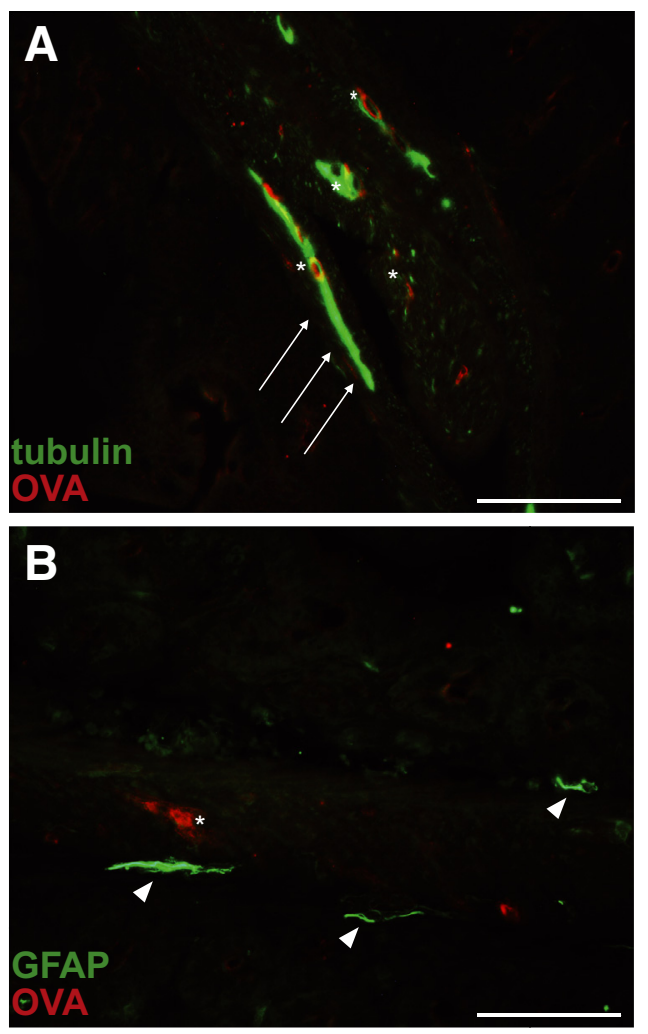

Figure 1 Expression of ovalbumin (OVA) in the enteric nervous system of CKTAC mice. A: OVA is prominently expressed on $\beta$-III-tubulin ${ }^{+}$enteric neurons (asterisks) of the submucosal plexus. Arrows point to a $\beta$-IIItubulin $^{+}$axon of a submucosal neuron. Immunofluorescence with rabbit anti-OVA (Cy3) and mouse anti- $\beta$-III-tubulin (fluorescein isothiocyanate). B: OVA is absent from glial fibrillary acidic protein (GFAP) ${ }^{+}$glial cells and their processes (arrowheads). Note a large $\mathrm{OVA}^{+}$neuron (asterisks). Immunofluorescence with rabbit anti-ovalbumin (Cy3) and mouse antiGFAP (FITC). Scale bars $=25 \mu \mathrm{m}$. Original magnification, $\times 200$. 

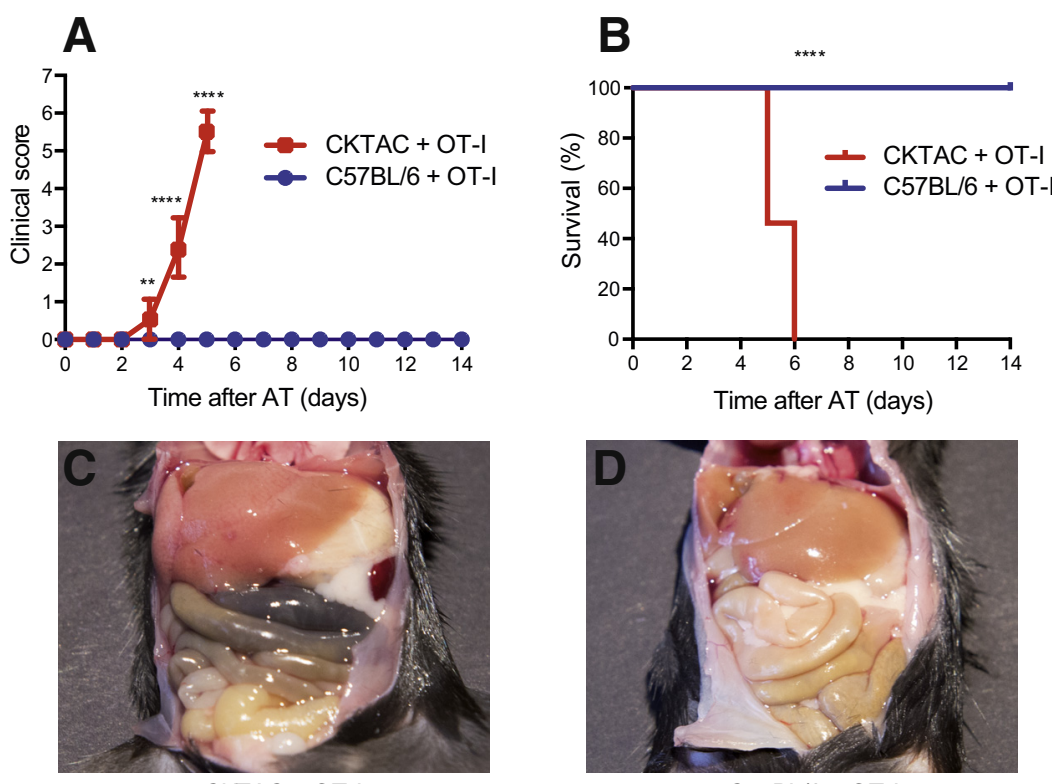

E

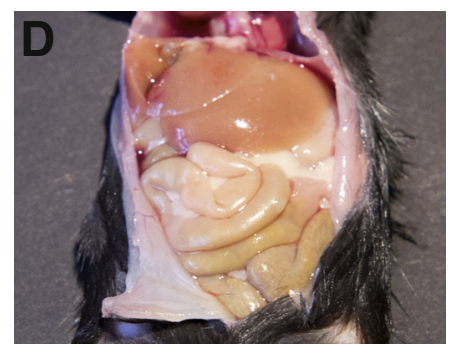

C57BL/6 + OT-I

Figure 2 Ovalbumin (OVA)-specific CD8 $T$ cells induce enteric ganglionitis in CKTAC mice. $\mathbf{A}$ and $\mathbf{B}$ : Clinical score (A) and survival rates (B) of CKTAC and C57BL/ 6 mice after adoptive transfer (AT) of $1 \times 10^{6}$ OTI CD8 T cells. Data represent one of the two experiments with six mice per group, which yielded similar results. C and D: Macroscopically, the distended and discolored colon of a CKTAC mouse (C) contrasts with the normal colon of a C567BL/ 6 mouse after AT of $1 \times 10^{6}$ OT-I CD8 $T$ cells (D). E: At least 50 high-power fields (HPF) per section immunostained for CD8 were quantitatively evaluated. F: CD8 T cells are closely attached to submucosal plexus neurons (arrows) after AT in a CKTAC mouse. The photomicrograph shows findings in a mouse representative of the entire experimental group. Anti-CD8 immunostaining, with counterstaining with hemalum. G: A submucosal CD8 T cell [fluorescein isothiocyanate (FITC)] expresses the early activation marker CD69 (Cy3). Immunofluorescence with rat anti-CD8 (FITC) and Armenian hamster anti-CD69 (Cy3). Data are expressed as means \pm SD (A and $\mathbf{E}) . n=6 .{ }^{* *} P<0.01$ $* * * P<0.0001$ CKTAC mice with AT versus C57BL/6 mice with AT ( $t$-test); ${ }^{{ }^{\dagger \dagger \dagger} P} P 0.0001$ versus C57BL/ 6 mice with AT. Scale bars: $25 \mu \mathrm{m}(\mathbf{F}) ; 80 \mu \mathrm{m}(\mathbf{G})$. Original magnification: $\times 200(\mathbf{F}) ; \times 600(\mathbf{G})$.
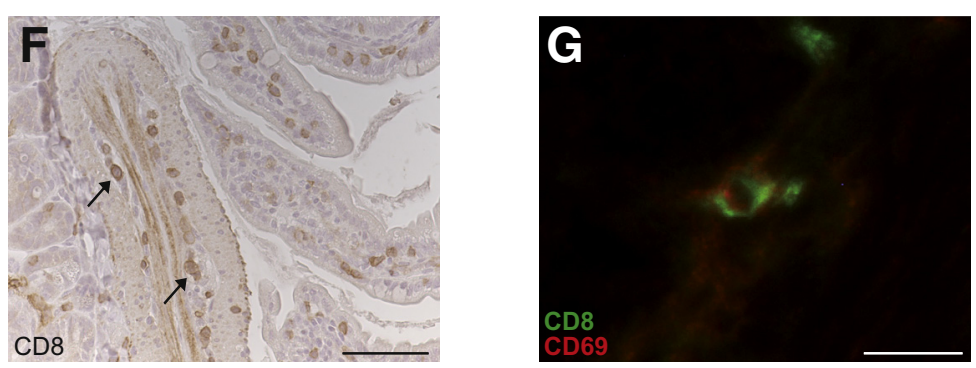

in the number of neurons and CD8 T cells in patients with symptoms for $<6$ or $\geq 6$ years, respectively, a two-tailed $t$-test was applied. For ethical reasons, control specimens from healthy individuals are not available.

\section{Results}

Characterization of Transgenic CKTAC Mice That Express OVA on Neurons of the Myenteric and Submucosal Plexus

To study whether autoimmune CD8 T cells may attack enteric neurons, CKTAC mice were generated. Throughout the ENS, these mice specifically express OVA on enteric neurons of the submucosal and myenteric plexus (Figure 1A). As expected, OVA expression was confined to neurons (Figure 1). Enteric glia was normal surrounding ganglia. Interstitial cells of Cajal had normal morphologic features with long cellular processes, physiologically expressed c-kit, and the CD34 antigen (Supplemental Figure S2). Smooth muscle cells regularly surrounded ganglia of the myenteric plexus. Thus, morphologic features of the ENS were normal.

CKTAC mice were observed for up to 1 year of age. They bred normally and did not have any spontaneous clinical abnormalities.

\section{OVA-Specific CD8 T Cells Cause Enteric Ganglionitis in CKTAC Mice}

OT-I CD8 T cells with AT caused rapidly progressing enterocolitis in CKTAC mice within 4 to 5 days (Figure 2, $\mathrm{A}$ and $\mathrm{B}$ ). In contrast to resistant C57BL/6 mice, the intestine of CKTAC mice became dark reddish discolored, 
A

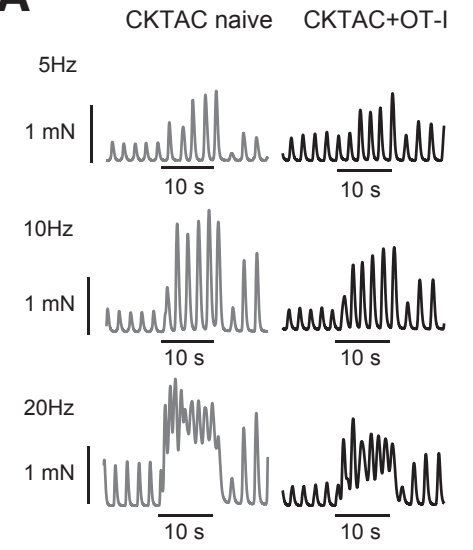

C
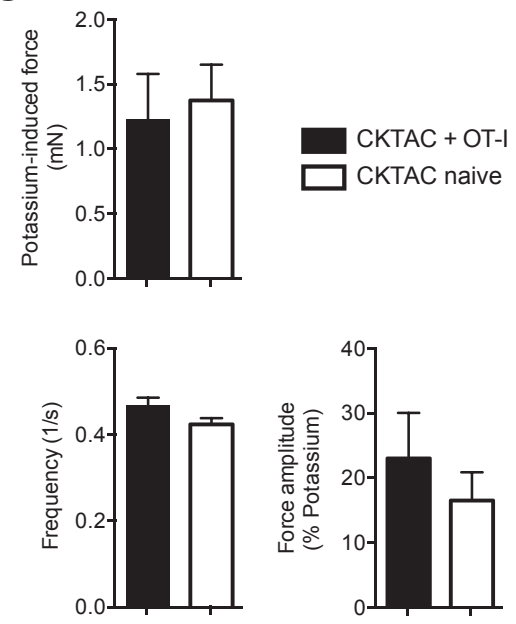

B

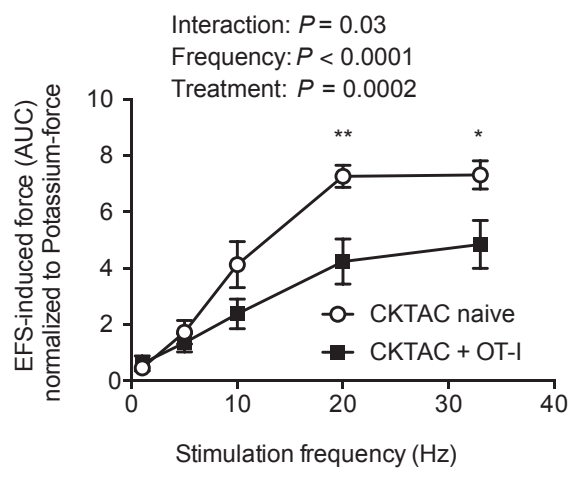

D

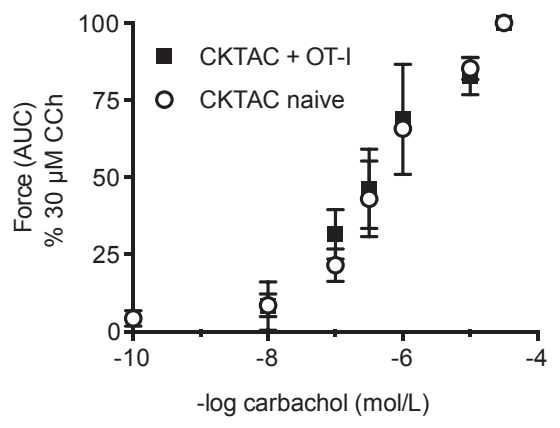

Figure 3 Effect of OT-I CD8 T cells on spontaneous, neuronally, and pharmacologically induced contractions of ileal smooth muscle of CKTAC mice. A: Original force tracings showing spontaneous rhythmic contractions and electrical field stimulation (EFS)induced contractions (10 seconds). EFS-mediated neuronal stimulation increases the amplitude of the rhythmic, phasic contractions at low frequencies $(<10$ $\mathrm{Hz}$ ) and increases tone with superimposed phasic contractions that eventually fused into tetanus at frequencies $>10 \mathrm{~Hz}$ in both groups. B: Summary of EFSinduced contractions [area under the curve (AUC) determined during the 10-second stimulation period] normalized to potassium $(80 \mathrm{mmol} / \mathrm{L})$-induced force. Potassium-induced force is not different between CKTAC with and without adoptive transfer (AT). C: Summary of potassium $(80 \mathrm{mmol} / \mathrm{L})$-induced contractions and frequency and mean force amplitude of spontaneous rhythmic contractions normalized to potassium-induced force. There is no significant difference in potassium-elicited force or in the frequency and amplitude of spontaneous rhythmic contractions between groups, indicating that smooth muscle function and pacemaker activity were not affected by AT. D: Summary of dose-response relationships to carbachol. Force was determined as AUC during the first $120 \mathrm{sec}-$ onds after application of carbachol. The $\mathrm{pEC}_{50}$ values ( $-\log$ of the concentrations necessary to elicit half maximal activation) of the dose-response relationships to the muscarinic agonist, carbachol, were not different between groups, suggesting that the sensitivity of postjunctional effectors to cholinergic neurotransmission is not decreased in ileal smooth muscle from CKTAC mice with AT. ${ }^{*} P<0.05,{ }^{*} * P<0.01$ CKTAC mice with AT versus C57BL/6 mice with AT (two-way analysis of variance; Sidaks multiple comparison posttest). CCh, carbachol. massively distended, and edematous (Figure 2, C and D), indicating ileus.

Force measurement in ileal preparations from CKTAC mice with and without AT of OT-I CD8 T cells, which exhibited spontaneous rhythmic contractions (Figure 3A), had a significantly attenuated contractile force at higher frequencies after AT (Figure 3B). Remarkably, smooth muscle function and pacemaker activity as well as the sensitivity of postjunctional effectors to cholinergic neurotransmission were not altered in ganglionitis (Figure 3, C and D).

Morphologically, Swiss role ${ }^{18,19}$ colonic preparations that allow analysis of all anatomical compartments, including both the submucosal and myenteric plexus, revealed enteric ganglionitis. CD $45^{+}$infiltrates mainly consisted of enlarged, activated $\mathrm{CD} 9^{+} \mathrm{CD} 8 \mathrm{~T}$ cells (Figure $2, \mathrm{E}-\mathrm{G}$ ). CD8 T cells were intimately attached to $\mathrm{OVA}^{+}$neurons of the submucosal and myenteric plexus (Figures $2 \mathrm{~F}$ and $4 \mathrm{~A}$ ). These $\mathrm{OVA}^{+} \beta$-III-tubulin ${ }^{+} \mathrm{MAP}^{+} \mathrm{HuC}^{+}{ }^{+}$neurons had upregulated the major histocompatibility complex (MHC) class I antigen (Figure 4, A-F) and were pushed into apoptosis (Figure 4, G-J). Twenty-four hours after onset of colitis-related symptoms, $60.3 \%$ of submucosal and myenteric plexus neurons were already lost (Figure $4 \mathrm{~K}$ ). Both plexuses were similarly affected $(52.1 \%$ and $66.6 \%$ for the submucosal and myenteric plexus, respectively, $P>0.05$ ). Only single $\mathrm{Iba1}^{+}$macrophages and CD4 T cells were scattered throughout the intestinal wall but were not preferentially associated with enteric neurons. To study whether CD4 T cells also contribute to disease, CD4 T cells were depleted in vivo (Supplemental Figure S3A). Neither the clinical course of disease nor the degree of neuronal loss were altered in CD4 T cell-depleted CKTAC mice compared with rat IgG-injected CKTAC mice on OT-I CD8 T cell AT (Supplemental Figure S3, B-D). Thus, these experiments exclude a relevant role of CD4 $\mathrm{T}$ cells in this model.

Gut inflammation induced an immune response in MLN and spleen, where OVA-specific CD8 T cells significantly increased in number and were activated as evidenced by an increased CD69 expression (Figure 5A). Furthermore, IFN$\gamma$ mRNA was significantly up-regulated in MLN and spleen (Figure 5B).

\section{IFN- $\gamma$ Mediates Destruction of Enteric Neurons}

The significant induction of IFN- $\gamma$ mRNA prompted us to determine its role in enteric ganglionitis. Indeed, IFN- $\gamma$ 


\section{CKTAC + OT-I}
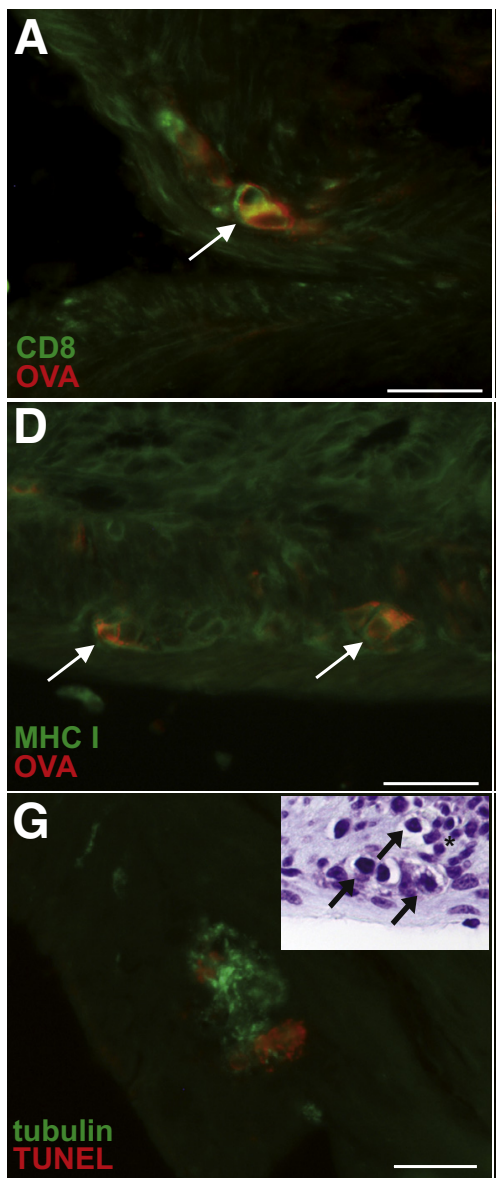

\section{$J$}

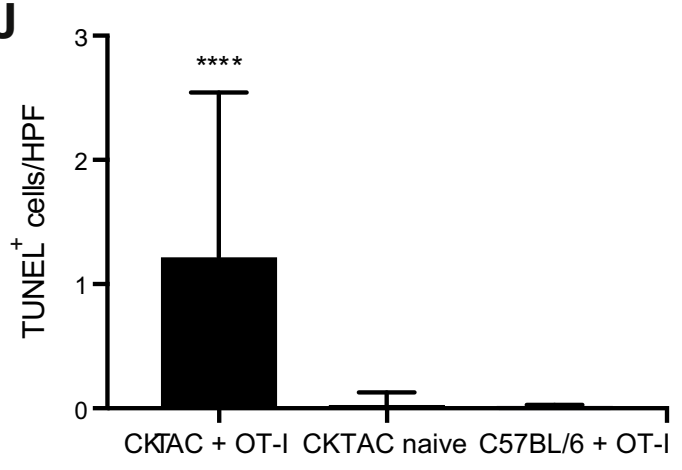

CKTAC naive
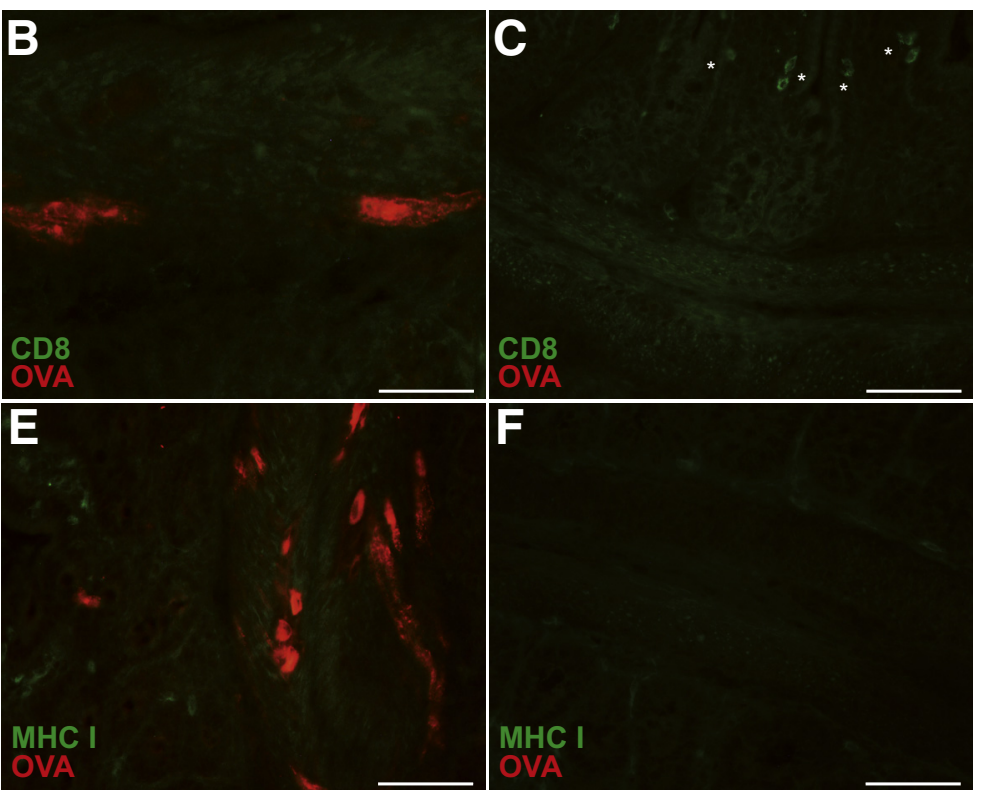

$\mathbf{F}$

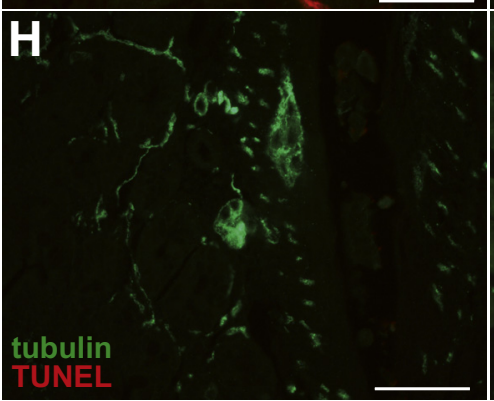

K

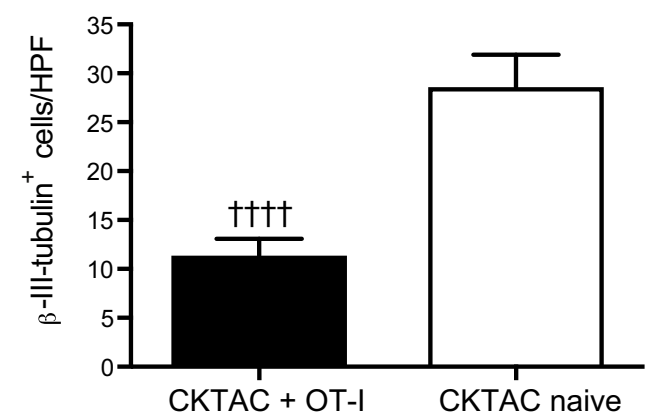

Figure 4 Characteristics of autoimmune enteric ganglionitis in CKTAC mice after adoptive transfer (AT) of $1 \times 10^{6}$ OT-I CD8 T cells. A: CD8 T cells [fluorescein isothiocyanate (FITC)] have homed to a submucosal plexus ovalbumin (OVA) $)^{+}$(Cy3) neuron (arrow). B: 0VA ${ }^{+}$(Cy3) enteric neurons are not associated with CD8 T cells (FITC) in a CKTAC mouse that had not received OT-I CD8 T cells. C: OVA (Cy3) is not expressed on enteric neurons of a C57BL/6 mouse. AT of OT-I CD8 T cells does not result in homing of CD8 T cells (FITC) to the enteric nervous system. Asterisks indicate small mucosal CD8 T cells. A-C: Immunofluorescence with rabbit anti-OVA (Cy3) and rat anti-CD8 (FITC). D: Submucosal plexus $0 \mathrm{VA}^{+}$(Cy3) neurons express the major histocompatibility complex (MHC) class I antigen (FITC, arrows). E: OVA ${ }^{+}$(Cy3) enteric neurons of a naïve CKTAC mouse do not express the MHC class I antigen (FITC). F: Neither OVA (Cy3) nor the MHC class I antigen (FITC) are expressed on enteric neurons in a C57BL/6 mouse that had received AT of 0T-I CD8 T cells. D-F: Immunofluorescence with rabbit anti-OVA (Cy3) and rat anti-MHC class I antigen (FITC). G: terminal deoxynucleotidyl transferase-mediated dUTP nick-end labeling $(\text { TUNEL) })^{+}$(TMR red) DNA strand breaks indicate apoptosis of a neuron with clumped $\beta$-III-tubulin fragments (FITC). Inset: Shrunken neurons with condensed nuclear chromatin (arrows) are surrounded by inflammatory cells (cresyl violet) (asterisk).H: In a naïve CKTAC mouse, $\beta$-III-tubulin ${ }^{+}$enteric neurons (FITC) are viable and thus do not harbor TUNEL ${ }^{+}$(TMR red) DNA strand breaks and are therefore not indicative of apoptosis. I: In a C57BL/6 mouse that had received an AT of OT-I CD8T cells, $\beta$-III-tubulin ${ }^{+}$enteric neurons (FITC) are viable and thus, do not harbor TUNEL ${ }^{+}$(TMR red) DNA strand breaks and are therefore not indicative of apoptosis. G-I: Immunofluorescence with TUNEL (TMR red) and rabbit anti- $\beta$-III-tubulin (FITC). J: The number of apoptotic cells was evaluated in at least 50 high-power fields (HPF) per section immunostained for TUNEL. A repeat experiment yielded similar results. K: The number of neurons was evaluated in at least $50 \mathrm{HPF}$ per section immunostained for $\beta$-III-tubulin. A repeat experiment yielded similar results. Data are expressed as means \pm SD (J and K). $n=6 .{ }^{* * * *} P<0.0001$ versus naive and C57BL/6 mice with AT ( $t$-test); ${ }^{\dagger \dagger \dagger} P<0.0001$ versus naive $(t$-test). Scale bars: $50 \mu \mathrm{m}(\mathbf{A}, \mathbf{B}$, and $\mathbf{D}) ; 25 \mu \mathrm{m}(\mathbf{C}, \mathbf{E}$, $\mathbf{F}$, and $\mathbf{H}) ; 120 \mu \mathrm{m}(\mathbf{G}) ; 12 \mu \mathrm{m}(\mathbf{I})$. Original magnification: $\times 400(\mathbf{A}, \mathbf{B}, \mathbf{D}$, and inset); $\times 200(\mathbf{C}, \mathbf{E}, \mathbf{F}$, and H); $\times 1000(\mathbf{G}) ; \times 100(\mathbf{I})$. 
neutralization significantly ameliorated disease (Figure 6, A and $\mathrm{B}$ ).

Macroscopically, the intestine of anti-IFN- $\gamma-$ treated CKTAC mice with AT was normal (Figure 6C). IFN- $\gamma$ neutralization did not impair CD8 T-cell homing to the neuromicroenvironment (Figure 7, A and B); thus, CD8 T cells were closely attached to enteric neurons (Figure 7, A and C). Remarkably, neurons did not up-regulate MHC class I antigen (Figure 7C), and neuronal apoptosis was less prominent compared with controls. Thus, $74.2 \%$ of submucosal and myenteric plexus neurons were preserved by anti-IFN- $\gamma$ treatment (Figure 7D).

In contrast, inducible nitric oxide synthase (iNOS) antagonization by L-NIL did not protect CKTAC mice from ganglionitis (Supplemental Figure S4, A and B). L-NIL and control treated CKTAC mice exhibited no differences either clinically nor morphologically (Supplemental Figure S4, C and D).

\section{CD8 T-Cell-Dominated Inflammation Is Followed by Loss of Enteric Neurons in Patients with GI Dysmotility}

In 30 patients with GI dysmotility in whom comprehensive clinical diagnostic workup did not identify an underlying origin, morphologic analysis of full-thickness colonic specimens revealed a colonic pathologic finding of two patterns, depending on disease duration. CD8 Tcell-dominated inflammation was the characteristic feature in patients with a clinical history $<6$ years (Supplemental Figure S5, A and E, and Supplemental Table S1). CD8 T cells were closely attached to MHC class $\mathrm{I}^{+} \mathrm{MAP}^{+} \beta$-IIItubulin $^{+} \mathrm{HuC} / \mathrm{D}^{+}$submucosal and myenteric plexus neurons (Figure 8, A, C, and G, and Supplemental Figure S5, A and E). Most neurons were vital (Figure 8, C and E). Only single CD4 T cells and $\mathrm{CD} 68^{+}$macrophages were scattered throughout the intestinal wall but were not preferentially associated with ganglia (Supplemental Figure S5, C, D, G, and $\mathrm{H})$. In patients with a clinical history $\geq 6$ years, the hallmark was a significant loss of $74.8 \%$ of MAP- $2^{+}$enteric neurons (Figure $8 \mathrm{H}$ ) similarly affecting the submucosal (76.4\%) and myenteric plexus (73.0\%), whereas inflammation was absent (Figure 8, B and G, Supplemental Figure S5, B, D, F, and H, and Supplemental Table S1). Ganglia were completely devoid of neurons or harbored only single $\mathrm{MAP}-2^{+} \beta$-III-tubulin ${ }^{+} \mathrm{HuC} / \mathrm{D}^{+}$neurons, which were MHC class I antigen ${ }^{-}$(Figure 8, D and F). Secondary changes (axonal degeneration, gliosis, fibrosis) prevailed (Supplemental Table S1).

\section{Discussion}

These studies in a novel mouse model strongly support the hypothesis that CD8 T-cell-mediated inflammation of the ENS plays a crucial role in GI dysmotility. IFN$\gamma$-dependent destruction of enteric neurons was recognized by autoreactive CD8 $\mathrm{T}$ cells as underlying mechanism. These experimental data mimic pathologic findings in the colon of patients with GI dysmotility that could not be assigned to a specific origin before pathologic analysis. In
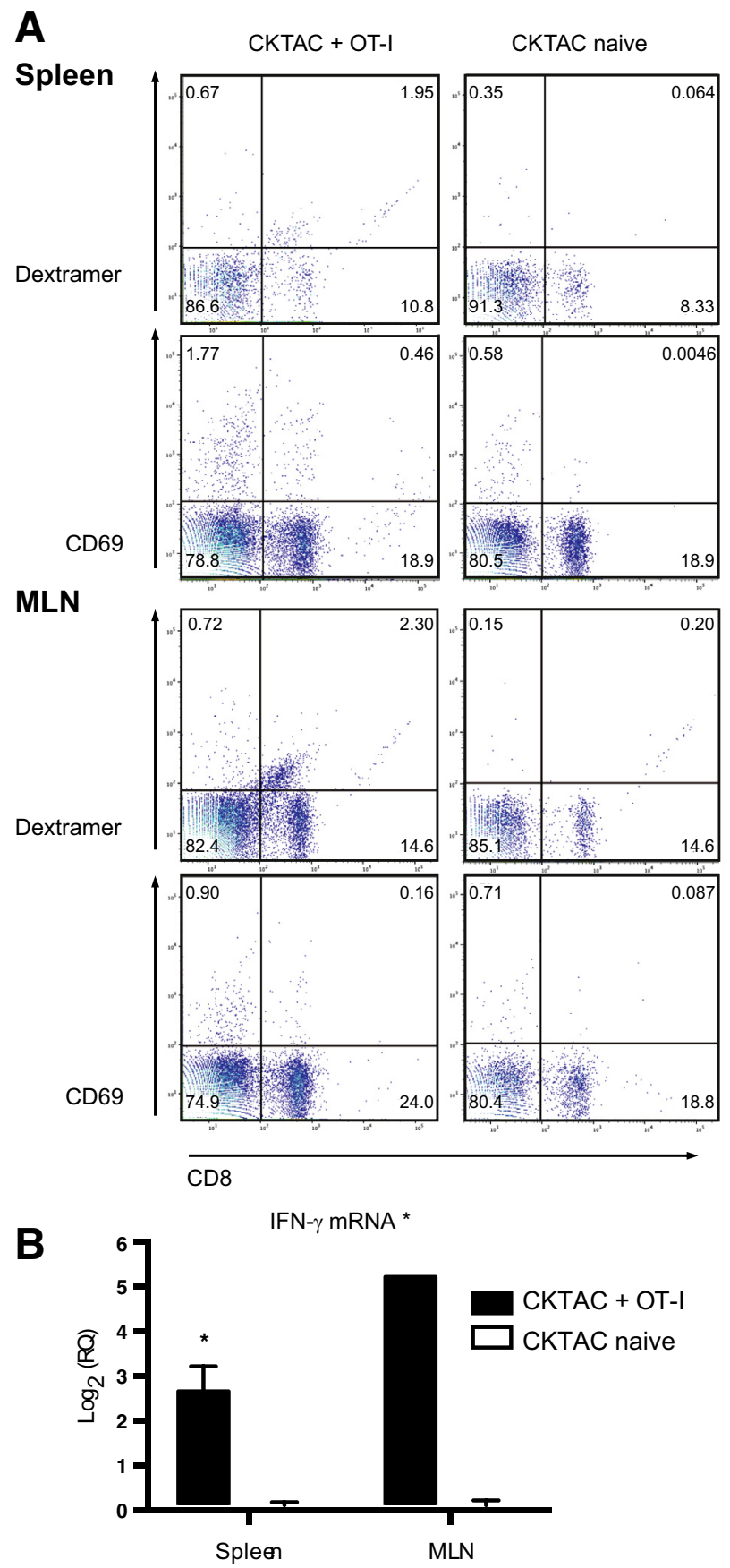

Figure 5 Flow cytometric characterization of CD8 T cells and interferon (IFN) $-\gamma$ mRNA transcription in CKTAC mice with adoptive transfer (AT) compared with CKTAC mice without AT. A: In the spleen and mesenteric lymph node (MLN) of CKTAC mice after AT, ovalbumin (OVA)-specific CD8 T cells increase in frequency and CD8 T cells are markedly activated. OVAspecific CD8 T cells were identified by combined CD8a expression and SIINFEKL dextramer staining. The activation state of CD8 T cells was detected by double staining with CD8a and CD69 antibodies. B: IFN- $\gamma$ mRNA transcription in spleen and MLN. Data are expressed as the mean $\log _{2}$-fold change in gene expression between CKTAC mice after AT and control CKTAC mice without AT (ie, naïve). $n=6 .{ }^{*} P<0.05$ versus naive ( $t$-test). 

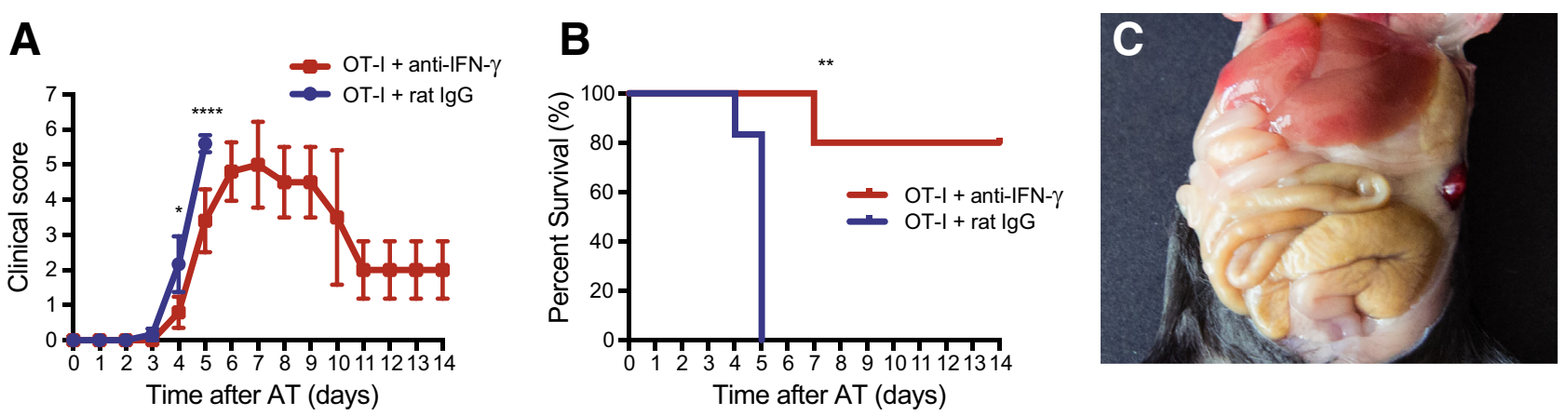

Figure 6 Interferon (IFN)- $\gamma$ antagonization significantly ameliorates autoimmune enteric ganglionitis in CKTAC mice. Clinical score (A) and survival rates (B) after adoptive transfer (AT) of $1 \times 10^{6}$ OT-I CD8 T cells of CKTAC mice treated intraperitoneally with anti-IFN- $\gamma$ or rat IgG. Data C: Macroscopically, the intestine of a CKTAC mouse with AT treated with anti-IFN- $\gamma$ is normal. Data represent one of two experiments, yielding similar results. Data are expressed as means \pm SD (A). $n=6 .{ }^{*} P<0.05,{ }^{* *} P<0.01$, and ${ }^{* * * *} P<0.0001$ CKTAC mice with AT + anti-IFN-gamma treatment versus CKTAC mice with AT + rat IgG ( $t$-test).

addition, patients with inflammatory bowel disease, including ulcerative colitis and Crohn disease, have a high prevalence of bowel dysmotility; aberrant bowel motility is linked to inflammatory burden and clinical symptoms. ${ }^{24-26}$

The observation that both the submucosal and myenteric plexuses were targeted by inflammation and neuronal destruction in humans was recapitulated in our experimental model. These data, which contrast with a predominant affection of the myenteric plexus, ${ }^{8,27}$ point to recognition of (an) antigen(s) shared by neurons of the submucosal and myenteric plexus, which still remain to be elucidated in humans. The exclusive CD8 T-cell composition of the inflammatory infiltrates in the microenvironment of the ENS in our series of 30 patients, which is at variance with a report on three patients in whom both CD4 and CD8 T cells contributed to the infiltrates ${ }^{28}$ strongly suggests a CD8 T-cell-mediated

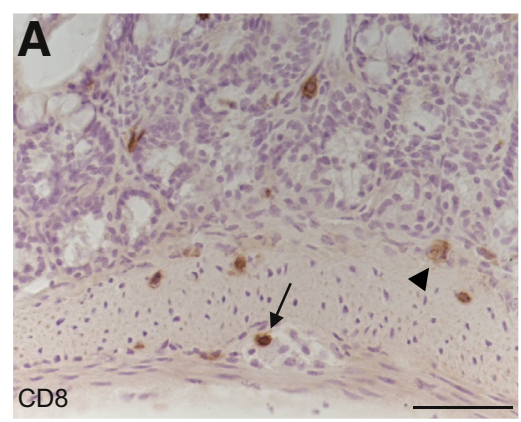

B
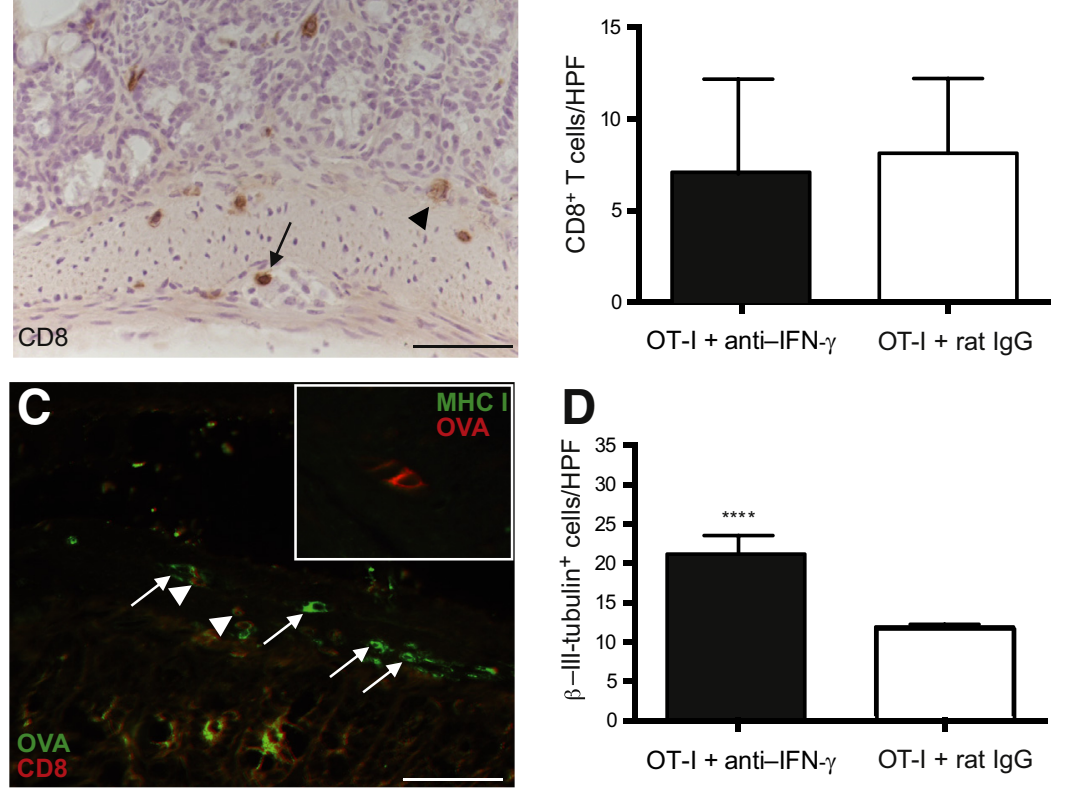

attack of neurons. Interestingly, one of the patients in the study by De Giorgio et $\mathrm{al}^{28}$ was biopsied twice; active inflammation early in disease was followed by myenteric neuronal loss. This observation fits well into our concept of a two-stage disease. Therapeutically relevant, patients in the inflammatory stage likely will benefit from immunosuppressive therapy. Indeed, some patients were susceptible to corticosteroids. ${ }^{28}$ In addition, cytokine blockade trials, including targeting IFN- $\gamma$, yielded promising results, which, unfortunately, were mostly not long-lasting. ${ }^{29,30}$ These overall rather disappointing results may be explained, at least in part, by the data indicating that the benefit of immunosuppression may be restricted to the inflammatory phase, whereas later, when $74.8 \%$ of enteric neurons are irreversibly lost, fibrosis- and gliosis-induced intestinal wall rigidity account for patients' ongoing concerns.

Figure 7 Interferon (IFN)- $\gamma$ neutralization protects CKTAC mice with adoptive transfer (AT) from autoimmune enteric ganglionitis. A: CD8 T cells are attached to a myenteric plexus neuron (arrow) and a submucosal plexus neuron (arrowhead) in an anti-IFN- $\gamma$-treated CKTAC mouse. Anti-CD8 immunostaining, with hemalum counterstaining. B: Homing of CD8 T cells to the submucosal and myenteric plexus is unimpaired by IFN- $\gamma$ neutralization. At least 50 high-power fields (HPF) per section immunostained for CD8 were quantitatively evaluated in CKTAC mice with AT that received either anti-IFN- $\gamma$ or rat IgG. A repeat experiment yielded similar results. C: In a CKTAC mouse, anti-IFN- $\gamma$ treatment preserves vitality of ovalbumin (OVA) ${ }^{+}$neurons [fluorescein isothiocyanate (FITC), arrows], even when associated with CD8 T cells (Cy3, arrowheads). Immunofluorescence with rabbit antiOVA (FITC) and rat anti-CD8 (Cy3). Inset: In an anti-IFN$\gamma$-treated CKTAC mouse, an OVA ${ }^{+}$(Cy3) neuron has not up-regulated the major histocompatibility complex (MHC) class I antigen (FITC). Immunofluorescence with rabbit anti-OVA (Cy3) and rat anti-MHC class I antigen (Cy3). D: The number of neurons was quantitatively evaluated in at least $50 \mathrm{HPF}$ per section immunostained for $\beta$-III-tubulin. A repeat experiment yielded similar results. Data are expressed as means \pm SD (B and D). $n=6$. $* * * * P<0.0001$ CKTAC mice with AT + anti-IFN-gamma treatment versus CKTAC mice with AT + rat IgG (t-test). Scale bars: $50 \mu \mathrm{m}(\mathbf{A}) ; 25 \mu \mathrm{m}$ (C). Original magnification: $\times 400($ A) $; \times 200($ C); $\times 400$ (inset). 
Clinical history $<6$ years
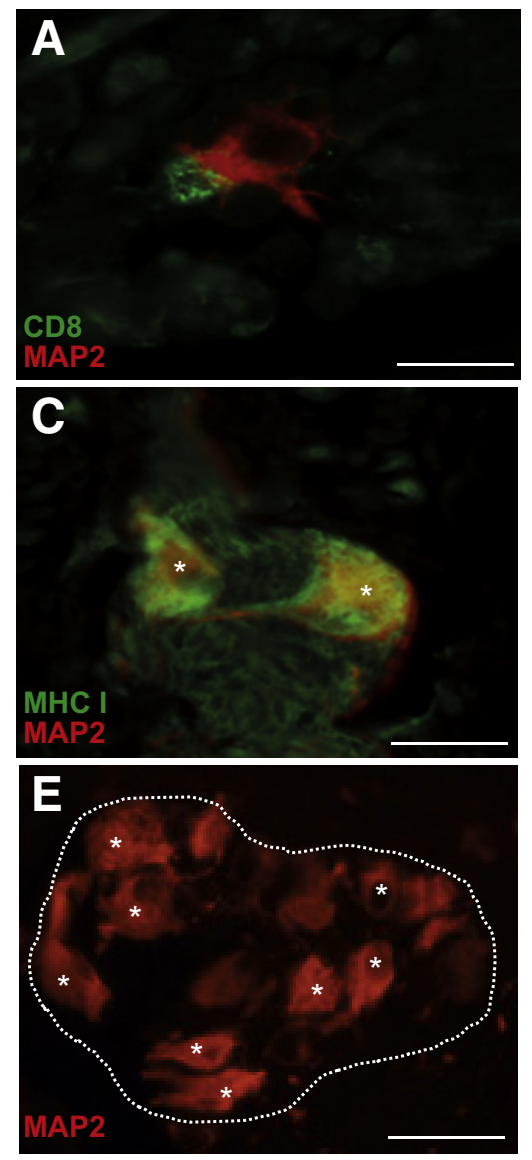

G

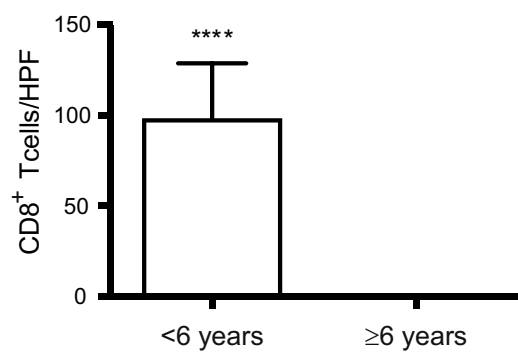

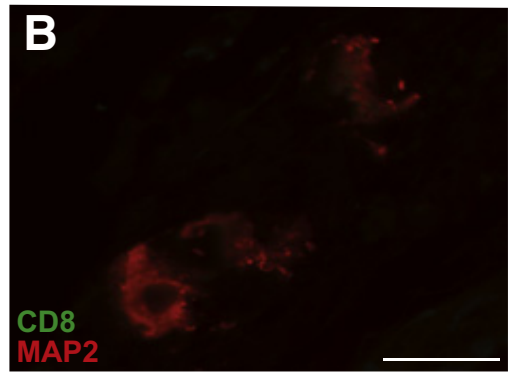

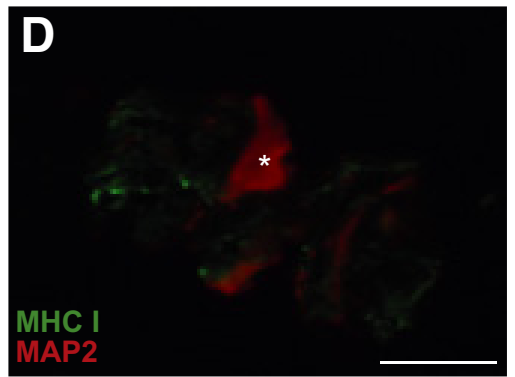

Clinical history $\geq 6$ years

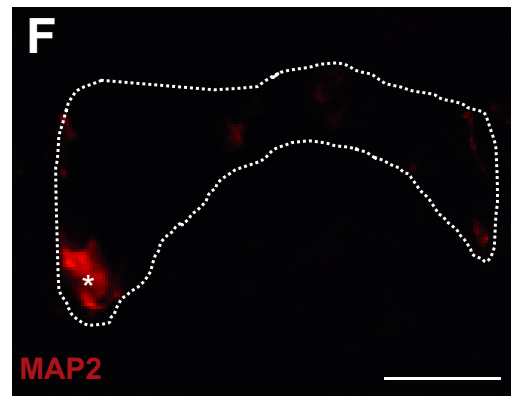

H

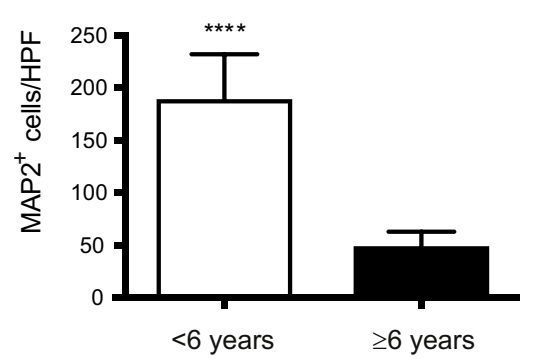

Figure 8 CD8 T-cell-mediated inflammation leads to neuronal loss in patients with gastrointestinal dysmotility. A and B: Intimate association of a CD8 T cell [fluorescein isothiocyanate (FITC)] with a MAP2 ${ }^{+}$neuron $(\mathrm{Cy} 3)$ in the inflammatory stage (A), whereas CD8 T cells (FITC) are completely absent from the myenteric plexus harboring single $\mathrm{MAP2}^{+}$neurons (Cy3) in a patient with a clinical history $\geq 6$ years (B). Immunofluorescence with rabbit antiCD8 (FITC) and mouse anti-MAP2 (Cy3). C and D: In the inflammatory stage of disease, $\mathrm{MAP2}^{+}$neurons (Cy3, asterisk) have up-regulated the major histocompatibility complex (MHC) class I antigen (FITC, C). MHC class I antigen (FITC) is not expressed on the only $\mathrm{MAP2}^{+}$neuron (Cy3, asterisk) still present in a myenteric plexus ganglion in a patient with a clinical history $\geq 6$ years (D). Immunofluorescence with mouse anti-MAP2 (Cy3) and rabbit anti-MHC class I antigen (FITC). E and F: Several large $\mathrm{MAP2}^{+}$neurons (Cy3, asterisks) in a myenteric plexus ganglion (dotted lines) in acute inflammation (E). In chronic disease $(\mathbf{F})$, there is only a single shrunken MAP2 ${ }^{+}$ neuron (Cy3, asterisk) in a myenteric plexus ganglion (dotted lines). Immunofluorescence with mouse antiMAP2 (Cy3). G and H: Numbers of CD8 T cells (G) and neurons $(\mathbf{H})$ in submucosal and myenteric ganglia. At least 25 high-power fields (HPF) per section immunostained for CD8 and MAP-2 were analyzed per patient. Data are expressed as means \pm SD. ${ }^{* * * *} P<0.0001$ versus patients with a clinical history $>6$ years ( $t$-test). Scale bars $=50$ $\mu \mathrm{m}(\mathbf{A}-\mathbf{F})$. Original magnification, $\times 400(\mathbf{A}-\mathbf{F})$.
The striking attachment of CD8 T cells to enteric neurons in patients' colonic specimens as well as in murine enteric ganglionitis strongly suggests a cytotoxic attack. Indeed, these neurons had up-regulated the MHC class I antigen, which renders them susceptible to antigen-specific recognition by CD8 T cells with subsequent destruction. IFN- $\gamma$, a highly potent inducer of MHC antigens on many cells, including damaged neurons, ${ }^{31,32}$ was identified as a decisive mediator because its in vivo antagonization significantly improved the clinical course of ganglionitis by rescuing most neurons from apoptosis. The observation that $74.2 \%$ but not all neurons were protected in CKTAC mice treated with anti-IFN- $\gamma$ raises the question of what further factors contribute to neuronal damage that still remain to be elucidated. However, antagonization of iNOS, an important mediator of gut physiology induced by IFN $-\gamma,{ }^{33}$ excluded its relevant role in autoimmune murine ganglionitis under these conditions. Similarly, depletion studies disclosed a clinically relevant function of $\mathrm{CD} 4 \mathrm{~T}$ cells, which might have affected CD8 T-cell function.

The target cell-specific damage of neurons without detrimental effects on other cell populations involved in regulation of GI motility, as evidenced morphologically and physiologically, is remarkable. These data suggest that neuronal function but not that of pacemaker or smooth muscle cells was impaired in this model. The data are further corroborated by a lack of effect of antagonization of iNOS, which acts on interstitial cells of Cajal and improves pacemaker potentials derived from these cells. $^{34}$ 
These observations of cell-specific damage are in line with studies on enteric glia. When glial fibrillary acidic protein-hemagglutinin mice, which express influenza virus hemagglutinin under the glial fibrillary acidic protein promoter, were crossed with hemagglutinin-specific T-cell receptor-expressing mice, they developed spontaneous jejuno-ileo-colitis as a consequence of CD8 T-cell infiltration with selective killing of hemagglutinin-expressing glial cells. ${ }^{35}$ Together, these data indicate that disease with similar clinical features and outcome can be induced by targeting enteric glia as well as neurons and that both cell populations of the ENS are indispensable for GI motility. Interestingly, the autoantigen-expressing cell seems to determine the fate of autoimmune CD8 T cells because OT-I CD8 T cells injected intravenously into transgenic mice, which express OVA in intraintestinal epithelial cells, were rendered tolerant. ${ }^{36}$ Collectively, these studies point to a high vulnerability of cells of the ENS against an autoimmune CD8 T-cell attack.

Although this transgenic model reflects important pathogenetic aspects of human GI dysmotility, there are also differences. The protracted course in patients contrasts with fulminant disease in mice. This fining may be explained by differences in number and antigen affinity of the autoimmune CD8 T cells. CKTAC mice with AT that prominently express OVA on the surface of virtually all enteric neurons harbor a significant number of high-affinity T-cell receptor transgenic CD8 $\mathrm{T}$ cells. In contrast, the human T-cell repertoire is diverse and includes high-affinity as well as low-affinity T-cell receptors. So far, our knowledge of potential autoantigens expressed by enteric neurons is limited, and candidates recognized by autoimmune CD8 T cells still remain to be deciphered.

A recent elegant study added muscularis macrophages as population relevant for ENS degeneration. In aging, a phenotypic shift from anti-inflammatory M2 to proinflammatory M1 macrophages was associated with an increase in cytokines and immune cells. Increased apoptosis and loss of neurons resulted in delayed GI transit. ${ }^{37}$ Collectively, these and our data together support the hypothesis that a proinflammatory milieu in the microenvironment of the ENS fosters an antigen-specific neuronal attack.

In conclusion, a CD8 T-cell-mediated autoimmune reaction that targets enteric neurons importantly contributes to GI dysmotilty. Further experiments are required to dissect the complex, finely tuned network in which ENS cells interact with immune cells and soluble mediators, also taking into account that the gut micromilieu is further influenced by the microbial commensal flora, food components, and, potentially, pathogenic infectious agents.

\section{Acknowledgments}

We thank Anja Blau, Mariana Carstov, Elena Fischer, and Doris Metzler for technical assistance. NSE-cre(CK1) mice were kindly provided by Dr. Luis F. Parada (University of Texas Southwestern Medical Center, Dallas, TX).

\section{Supplemental Data}

Supplemental material for this article can be found at https://doi.org/10.1016/j.ajpath.2018.11.016.

\section{References}

1. Halvorson HA, Schlett CD, Riddle MS: Postinfectious irritable bowel syndrome-a meta-analysis. Am J Gastroenterol 2006, 101:1894-1899

2. Thabane M, Kottachchi DT, Marshall JK: Systematic review and metaanalysis: the incidence and prognosis of post-infectious irritable bowel syndrome. Aliment Pharmacol Ther 2007, 26:535-544

3. Dunlop SP, Jenkins D, Spiller RC: Distinctive clinical, psychological, and histological features of postinfective irritable bowel syndrome. Am J Gastroenterol 2003, 98:1578-1583

4. Spiller RC: Postinfectious irritable bowel syndrome. Gastroenterology 2003, 124:1662-1671

5. Gulbransen BD, Bashashati M, Hirota SA, Gui X, Roberts JA, MacDonald JA, Muruve DA, McKay DM, Beck PL, Mawe GM, Thompson RJ, Sharkey KA: Activation of neuronal P2X7 receptorpannexin-1 mediates death of enteric neurons during colitis. Nat Med 2012, 18:600-604

6. Linden DR, Couvrette JM, Ciolino A, McQuoid C, Blaszyk H, Sharkey KA, Mawe GM: Indiscriminate loss of myenteric neurones in the TNBS-inflamed guinea-pig distal colon. Neurogastroenterol Motil 2005, 17:751-760

7. Benyahia B, Liblau R, Merle-Beral H, Tourani JM, Dalmau J, Delattre JY: Cell-mediated autoimmunity in paraneoplastic neurological syndromes with anti-Hu antibodies. Ann Neurol 1999, 45:162-167

8. De Giorgio R, Guerrini S, Barbara G, Stanghellini V, De Ponti F, Corinaldesi R, Moses PL, Sharkey KA, Mawe GM: Inflammatory neuropathies of the enteric nervous system. Gastroenterology 2004, $126: 1872-1883$

9. Dropcho EJ: Remote neurologic manifestations of cancer. Neurol Clin 2002, 20:85-122. vi

10. Voltz RD, Posner JB, Dalmau J, Graus F: Paraneoplastic encephalomyelitis: an update of the effects of the anti-Hu immune response on the nervous system and tumour. J Neurol Neurosurg Psychiatry 1997, 63:133-136

11. Lutt A, Michel K, Kruger D, Volz MS, Nassir M, Schulz E, Poralla L, Tangermann P, Bojarski C, Holtje M, Teegen B, Stocker W, Schemann M, Siegmund B, Pruss H: High prevalence and functional effects of serum antineuronal antibodies in patients with gastrointestinal disorders. Neurogastroenterol Motil 2018, 30:e13292

12. Pimentel M, Morales W, Pokkunuri V, Brikos C, Kim SM, Kim SE Triantafyllou K, Weitsman S, Marsh Z, Marsh E, Chua KS, Srinivasan S, Barlow GM, Chang C: Autoimmunity links vinculin to the pathophysiology of chronic functional bowel changes following Campylobacter jejuni infection in a rat model. Dig Dis Sci 2015, 60:1195-1205

13. Goin JC, Sterin-Borda L, Bilder CR, Varrica LM, Iantorno G Rios MC, Borda E: Functional implications of circulating muscarinic cholinergic receptor autoantibodies in chagasic patients with achalasia Gastroenterology 1999, 117:798-805

14. Van Voorhis WC, Schlekewy L, Trong HL: Molecular mimicry by Trypanosoma cruzi: the F1-160 epitope that mimics mammalian nerve can be mapped to a 12-amino acid peptide. Proc Natl Acad Sci U S A 1991, 88:5993-5997

15. Sanchez-Ruiz M, Wilden L, Muller W, Stenzel W, Brunn A, Miletic H, Schluter D, Deckert M: Molecular mimicry between neurons and an intracerebral pathogen induces a CD8 T cell-mediated autoimmune disease. J Immunol 2008, 180:8421-8433 
16. Kwon CH, Zhou J, Li Y, Kim KW, Hensley LL, Baker SJ, Parada LF: Neuron-specific enolase-cre mouse line with cre activity in specific neuronal populations. Genesis 2006, 44:130-135

17. Schluter D, Deckert-Schluter M, Lorenz E, Meyer T, Rollinghoff M, Bogdan C: Inhibition of inducible nitric oxide synthase exacerbates chronic cerebral toxoplasmosis in Toxoplasma gondii-susceptible C57BL/6 mice but does not reactivate the latent disease in T. gondiiresistant BALB/c mice. J Immunol 1999, 162:3512-3518

18. Bialkowska AB, Ghaleb AM, Nandan MO, Yang VW: Improved swissrolling technique for intestinal tissue preparation for immunohistochemical and immunofluorescent analyses. J Vis Exp 2016, 113:e54161

19. Moolenbeek C, Ruitenberg EJ: The "Swiss roll": a simple technique for histological studies of the rodent intestine. Lab Anim 1981, 15:57-59

20. Brunn A, Mihelcic M, Carstov M, Feind L, Wieser EC, Schmidt J, Utermohlen O, Deckert M: Toll-like receptor 2, toll-like receptor 4, myeloid differentiation response gene 88, and toll-IL-1 receptor domain-containing adaptor-inducing interferon-gamma (TRIF) selectively regulate susceptibility of P0106-125-induced murine experimental autoimmune neuritis. Am J Pathol 2017, 187:42-54

21. Brunn A, Utermohlen O, Carstov M, Sanchez-Ruiz M, Miletic H, Schlüter D, Deckert M: CD4 T cells mediate axonal damage and spinal cord motor neuron apoptosis in murine P0106-125-induced experimental autoimmune neuritis. Am J Pathol 2008, 173:93-105

22. Eifinger F, Lubomirov LT, Dercks E, Genchev B, Roth B, Neiss WF, Pfitzer G, Schroeter MM: Neonatal mouse ileum: functional properties and protein composition of the contractile machinery. Pediatr Res 2014, 76:252-260

23. Lubomirov LT, Papadopoulos S, Putz S, Welter J, Klockener T, Weckmuller K, Ardestani MA, Filipova D, Metzler D, Metzner H, Staszewski J, Zittrich S, Gagov H, Schroeter MM, Pfitzer G: Agingrelated alterations in eNOS and nNOS responsiveness and smooth muscle reactivity of murine basilar arteries are modulated by apocynin and phosphorylation of myosin phosphatase targeting subunit-1. J Cereb Blood Flow Metab 2017, 37:1014-1029

24. Abdalla SM, Kalra G, Moshiree B: Motility evaluation in the patient with inflammatory bowel disease. Gastrointest Endosc Clin N Am 2016, 26:719-738

25. Menys A, Makanyanga J, Plumb A, Bhatnagar G, Atkinson D, Emmanuel A, Taylor SA: Aberrant motility in unaffected small bowel is linked to inflammatory burden and patient symptoms in Crohn's disease. Inflamm Bowel Dis 2016, 22:424-432

26. Bickelhaupt S, Pazahr S, Chuck N, Blume I, Froehlich JM, Cattin R, Raible S, Bouquet H, Bill U, Rogler G, Frei P, Boss A, Patak MA:
Crohn's disease: small bowel motility impairment correlates with inflammatory-related markers C-reactive protein and calprotectin. Neurogastroenterol Motil 2013, 25:467-473

27. Schobinger-Clement S, Gerber HA, Stallmach T: Autoaggressive inflammation of the myenteric plexus resulting in intestinal pseudoobstruction. Am J Surg Pathol 1999, 23:602-606

28. De Giorgio R, Barbara G, Stanghellini V, De Ponti F, Salvioli B, Tonini M, Velio P, Bassotti G, Corinaldesi R: Clinical and morphofunctional features of idiopathic myenteric ganglionitis underlying severe intestinal motor dysfunction: a study of three cases. Am J Gastroenterol 2002, 97:2454-2459

29. Furfaro F, Gilardi D, Allocca M, Cicerone C, Correale C, Fiorino G, Danese S: IL-23 Blockade for Crohn's disease: next generation of anti-cytokine therapy. Expert Rev Clin Immunol 2017, 13:457-467

30. Reinisch W, de Villiers W, Bene L, Simon L, Racz I, Katz S, Altorjay I, Feagan B, Riff D, Bernstein CN, Hommes D, Rutgeerts P, Cortot A, Gaspari M, Cheng M, Pearce T, Sands BE: Fontolizumab in moderate to severe Crohn's disease: a phase 2, randomized, doubleblind, placebo-controlled, multiple-dose study. Inflamm Bowel Dis 2010, 16:233-242

31. Deckert-Schluter M, Bluethmann H, Kaefer N, Rang A, Schluter D: Interferon-gamma receptor-mediated but not tumor necrosis factor receptor type 1- or type 2-mediated signaling is crucial for the activation of cerebral blood vessel endothelial cells and microglia in murine Toxoplasma encephalitis. Am J Pathol 1999, 154:1549-1561

32. Neumann H, Cavalie A, Jenne DE, Wekerle H: Induction of MHC class I genes in neurons. Science 1995, 269:549-552

33. Stuehr DJ, Marletta MA: Further studies on murine macrophage synthesis of nitrite and nitrate. IARC Sci Publ 1987, 84:335-339

34. Kaji N, Nakayama S, Horiguchi K, Iino S, Ozaki H, Hori M: Disruption of the pacemaker activity of interstitial cells of Cajal via nitric oxide contributes to postoperative ileus. Neurogastroenterol Motil 2018, 30:e13334

35. Cabarrocas J, Savidge TC, Liblau RS: Role of enteric glial cells in inflammatory bowel disease. Glia 2003, 41:81-93

36. Liu Z, Lefrancois L: Intestinal epithelial antigen induces mucosal CD8 $\mathrm{T}$ cell tolerance, activation, and inflammatory response. J Immunol 2004, 173:4324-4330

37. Becker L, Nguyen L, Gill J, Kulkarni S, Pasricha PJ, Habtezion A: Age-dependent shift in macrophage polarisation causes inflammationmediated degeneration of enteric nervous system. Gut 2018, 67: $827-836$ 